\title{
Autophagy inhibitor sensitizes MCF-7 breast cancer cells to novel cyclic tetrapeptide CTS203-induced caspase-9-dependent apoptotic cell death
}

\author{
S. WANG ${ }^{1}, \mathrm{X} . \mathrm{LI}^{1, \star}, \mathrm{Q} . \mathrm{WANG}^{2}$, Z. XIU ${ }^{1}$ \\ ${ }^{1}$ School of Life Science and Biotechnology, Dalian University of Technology, Dalian 116024, China; ${ }^{2}$ School of Pharmaceutical Science and Tech- \\ nology, Dalian University of Technology, Dalian 116024, China \\ *Correspondence: lxhxh@dlut.edu.cn
}

Received June 27, 2014 / Accepted August 27, 2014

\begin{abstract}
Histone deacetylase (HDAC) inhibitors have been demonstrated to be effective anti-cancer candidates against aggressive malignancies. In previous study, a novel hydroxamic acid derivate, CTS203 cyclo(-L-Asu(NHOH)-L-A3mc6c-L-Phe-D-Pro-), demonstrated promising HDAC inhibitory activity. Herein, more biological evaluations including cell viability, cell cycle distribution, cellular morphology, expression quantification as well as protein-protein interactions were measured to investigate its cytotoxic mechanism. Corresponding with its significant HDAC inhibitory activity, CTS203 led to increased acetylation of H3K14, cell cycle arrest as well as consequent apoptotic cell death, with bearable influence on the viability of normal cells. However, schedule-dependent cytotoxicity against MCF-7 breast cancer cells revealed a delayed cellular response to chemo-stimuli. Within this corresponding period, autophagy was rapidly triggered once exposure started, whereas autophagy inhibitor sensitized MCF-7 cells to CTS203, exhibiting synergistically anti-proliferative effects. The expression variation in MCF-7 cells revealed that the cleavage of Beclin 1 mediated by caspase- 8 resulted in disabled autophagy, thus ultimately facilitated and fastened caspase-9-dependent apoptotic cell death. Taken together, these findings elucidated the mechanism of CTS203-induced cytotoxicity as well as suggested that appropriate manipulation of autophagy would be an adjunctive strategy to enhance HDAC inhibitor-induced cell death.
\end{abstract}

Key words: cyclic tetrapeptide, apoptosis, autophagy, HDAC inhibitor, Beclin 1 cleavage

By manipulating the pattern of histone acetylation, HDAC inhibitors display a broad spectrum of cytotoxicity against various cancer cell lines. According to whole gene expression profile, an increasing number of non-histone proteins including transcription regulators, signal transduction mediators and structural proteins are being identified as substrates of HDACs [1]. Therefore, different phenotypes including cell cycle arrested, apoptosis and autophagy would be simultaneously or individually triggered upon HDAC inhibitor treatment [2-3]. Accordingly, the specific cellular response evoked by individual HDAC inhibitor appears depending on particular cell context such as the nature of stimuli, treatment concentration and exposure time [4].

Apoptosis usually plays essential roles in HDAC inhibitorinduced cell death and could be activated through intrinsic (caspase-9-dependent) and/or extrinsic (caspase-8-dependent) pathway. Once apoptosis occurred, caspases are called upon to coordinate as well as execute the process. Furthermore, emerging evidence has revealed that autopahgy could be alternatively induced in apoptosis-deficient cells, which suggested that apoptosis and autophagy may share complementary roles during regulation of cell death [5-6]. However, autophagy may otherwise facilitate cell survive [7]. Accordingly, many reports argued that elevation of autophagy is somehow related to drugresistance and autophagy inhibition enhances chemo-induced apoptotic cell death [8-9]. Therefore, in addition to augment of apoptotic response, appropriate mediation of autophagy should be specifically considered during certain treatment.

Cyclic tetrapeptide are a structurally complex group of HDAC inhibitors. Individuals belonging to this subfamily are usually active at nanomolar levels, yet exhibiting unique cytotoxicity profile [10]. In our previous study, a novel synthetic cyclic hydroxamic acid-containing peptides (CHAPs), CTS203 (cyclo(-1-Asu(NHOH)-1-A3mc6c-l-Phe-d-Pro-)), was screened out and possessed potent HDAC inhibitory activities [11]. To date, breast cancer is still one predominant type 
of the most common malignancies and the second leading cause of cancer mortality in females, though it is occasionally predictable or even curable in many cases [12-13]. Herein, we investigated the anti-cancer profile of CTS203 and the corresponding mechanisms underlying CTS203-induced cell death in human MCF-7 breast cancer cells. Aim to achieve this goal, cell viability, cell cycle distribution, apoptosis and autophagy associated molecules were measured. Our data would clearly demonstrate the anti-cancer efficiency of CTS203 and offer new insight into the therapeutic benefits of focusing on the crosstalk between apoptosis and autophagy.

\section{Materials and methods}

Compounds and reagents. CTS203 was prepared as previously described (HPLC, purity $>97 \%$ ) [11]. Trichostatin A (TSA) was purchased from Sigma-Aldrich (St. Louis, USA). 3-Methyladenine (3-MA) was purchased from Acros Organics (N), USA).

Before usage, CTS203 was dissolved in DMSO (Merk, Germany) and was diluted to the appropriate concentration using culture medium containing $10 \%$ fetal bovine serum (FBS, Gibco, USA). The final concentration of DMSO was less than $0.1 \%(v / v)$.

Cell culture. All of the malignancy cell lines as well as normal liver cell line L02 were obtained from the Cell Bank of Chinese Academy of Sciences (Shanghai, China). Primary hepatocytes were isolated from Kunming mice (kindly provided by Dr. Y. Dong). All animal procedures were performed following the protocol approved by the Institutional Animal Care and Use Committee. Cells were maintained in RPMI 1640 medium supplemented with 10\% FBS in a humidified atmosphere with $5 \% \mathrm{CO}_{2}$ at $37^{\circ} \mathrm{C}$. Growth medium was routinely changed every $24 \mathrm{~h}$.

Growth inhibition assay. Cell viability was measured via 3-(4,5-dimethylthiazol-2-yl)-2,5-diphenyl tetrazolium bromide (MTT, Sigma Aldrich, USA) assay.

For $\mathrm{IC}_{50}$ determination, cells were seeded in 96-well plates at a density of $2 \times 10^{3}$ per well. Cells were allowed to attach for $24 \mathrm{~h}$ and then exposed to various concentrations of indicated compounds. Cells exposed to DMSO under the same conditions were used as vehicle control. After incubation for specified time period, $20 \mu \mathrm{l}(5 \mathrm{mg} / \mathrm{ml})$ of MTT was added to each well. After incubation for another $4 \mathrm{~h}$, for all the solid tumor cell lines, the supernatant was aspirated and the formazan crystals were dissolved in DMSO. For leukemia cell lines, lysis solution $(50 \% \operatorname{DMF}(v / v), 30 \%$ SDS $(w / v)$ in distilled water) instead of DMSO was specially used to dissolve the metabolic product. After gentle agitation for $10 \mathrm{~min}$, the absorbance per well were ultimately measured by a microplate reader (Thermo Fisher Scientific, USA) at 570/630 nm.

To determine the schedule-dependent cytotoxicity of CTS203, cells were treated for indicated time and then removed to normal culture medium for recovery. After successive incubation for $24 \mathrm{~h}$ in normal medium, cell viability was then examined as according to the procedure described above. The inhibition percentage was calculated as follow:

$$
\begin{aligned}
& \text { Inhibition Percentage }(\%)=\left(1-\left(A_{57 \text { arreated }}-A_{63 \text { dreated }}\right) /\right. \\
& \left./\left(A_{57 \text { ountreated }}-A_{630 \text { untreated }}\right)\right) \times 100 \%
\end{aligned}
$$

Flow cytometry analysis. Cell cycle distribution was determined via propidium iodide (PI, Sigma Aldrich, USA) staining. Briefly, cells were seeded in 6-well plates and treated with indicated concentrations of CTS203 for $24 \mathrm{~h}$. After incubation, cells were harvest by centrifugation for $5 \mathrm{~min}$ at $2000 \mathrm{rpm}$ and then fixed with $75 \%$ cold ethanol overnight. After washing twice with cold PBS, cell pellets were suspended in $200 \mu \mathrm{l}$ PI solution $(50 \mu \mathrm{g} / \mathrm{ml}, 1 \%$ Triton X-100 $(v / v)$ in PBS). The stained cell pellets were finally measured using a flow cytometry system (BD, USA) and the results were analyzed using Mod Fix LT3.0 software.

Apoptotic cell death was detected using an Annexin V/PI apoptosis detection kit (KeyGen, China). Briefly, cells were seeded in 6-well plates, treated with indicated compounds for $12 \mathrm{~h}$. After treatment, cells were harvested and re-suspended in binding buffer. Staining solution was added according to the manufacture's instructions before measurement.

Fluorescence microscopy. Morphological changes of nuclei were determined by Hoechst 33342 staining. Briefly, MCF-7 cells were grown on cover slips. After indicated treatment, cells were washed with PBS solution and then fixed with $4 \%$ paraformaldehyde (PA, AMERSCO, USA) for $90 \mathrm{~s}$, then stained with Hoechst 33342 (AMERESCO, USA) for $20 \mathrm{~min}$ in darkness at room temperature. After washing with PBS, the stained cells were ultimately examined under a fluorescence microscope (Olympus 1X71, Japan).

Immunofluorescence assay (IF). Analysis of LC 3 amounts was detected via immunofluorescence. After indicated treatment for $24 \mathrm{~h}$, cells grown on cover slips were rinsed twice with PBS, then fixed by $4 \%$ cold PA for $20 \mathrm{~min}$ at room temperature. After washing, the fixed cells were permeabilized by PBS-T solution (0.1\% Triton X-100 in PBS) then blocked with PBS-B solution ( $4 \%$ BSA (Thermo Fisher Scientific, USA)) for $30 \mathrm{~min}$ at $37^{\circ} \mathrm{C}$, followed by incubation with primary anti-LC3 antibody (1:100, Abcam, UK) at $4{ }^{\circ} \mathrm{C}$ overnight. After washing 3 times with PBS, cells were incubated with FITC-labeled secondary antibody (1:200, Thermo, USA) for $1 \mathrm{~h}$ at room temperature. To visualize the alteration in nucleus region of the FITC-labeled cells, Hoechst 33342 was added 15 min before examination. Finally, cells were rinsed in PBS and examined under a confocal microscope (Olympus FV1000, Japan).

Western blot analysis. The expression levels of target proteins were detected by western blot. To standardize protein input, $\beta$-actin (1:1500, Santa Cruz, USA) was used as internal reference. Band intensities were quantified by Image J software.

Briefly, cells were harvested and whole cell extracts were prepared after indicated treatment. Cell lysates were clarified by centrifugation at $12000 \mathrm{rpm}$ for $10 \mathrm{~min}$ at $4{ }^{\circ} \mathrm{C}$ then pro- 
<smiles>CC(=CC(C)C(=O)c1ccc(N(C)C)cc1)C=C(C)C(=O)NO</smiles>

Trichostatin A (TSA)

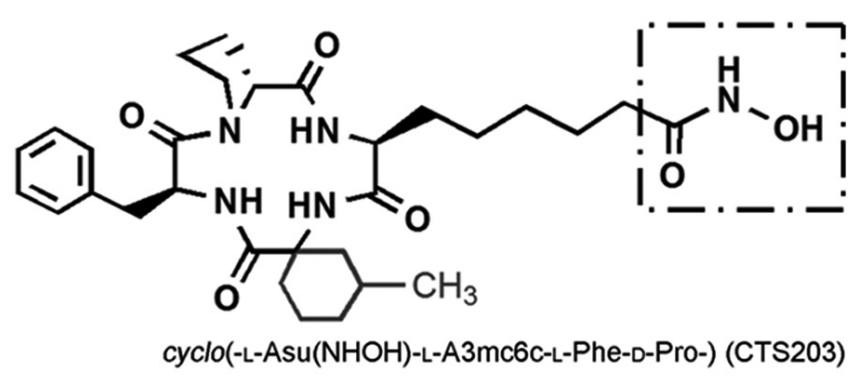

B

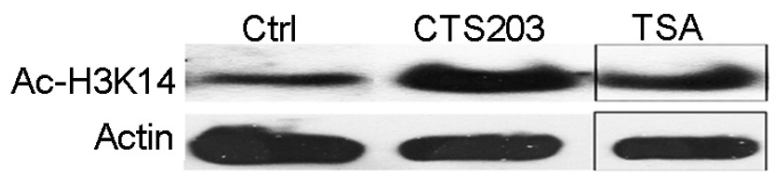

Figure 1. Anti-cancer potential of CTS203. (A) Pharmacophore features of CTS203. (B) Effects of CTS203 on H3K14 acetylation. Whole-cell extracts were prepared after indicated treatment for $24 \mathrm{~h}$, followed by Western blot analysis. Cells cultured in normal medium were used as negative control (Ctrl.), while the ones under TSA treatment were used as positive control. Equal loading and transfer were verified by probing the membranes with $\beta$-actin antibody.

tein concentration was quantified using BCA protein assay kit (KeyGen, China). After denaturation by boiling, proteins were separated using 15\% SDS-PAGE gel and transferred onto PVDF membranes (Millipore, USA) using a semi-dry blotting system. The transferred membrane was blocked in TBS-T saline $(0.05 \%(v / v)$ Tween-20) with 5\% $(w / v)$ nonfat milk, subsequently incubated overnight probing with specific primary antibodies (rabbit monoclonal anti-acetylated H3K14, 1:1000, Abcam, HK; mouse monoclonal anti-casase-8, 1:1000, Thermo Fisher Scientific, USA; mouse monoclonal anti-caspase-9, 1:1000, Thermo Fisher Scientific, USA; rabbit polyclonal anti-cytochrome $c, 1: 600$; rabbit polyclonal anti-Beclin 1,
1:800, Proteintech, USA; rabbit polyclonal anti-LC3, 1:500, Abcam, $\mathrm{HK}$ ) at $4{ }^{\circ} \mathrm{C}$ overnight. After washing, the membrane was incubated with HRP-conjugated goat anti-rabbit or antimouse secondary antibody (1:2000, Santa Cruz, USA) for 1 $\mathrm{h}$ at $37^{\circ} \mathrm{C}$, then corresponding protein bands were visualized using an ECL kit (Thermo Fisher Scientific, USA) according to the manufacturer's instructions.

Immunoprecipitation assay (IP). To determine the interaction between protein molecules, whole cell extract was prepared using non-SDS lysis buffer for $1 \mathrm{~h}$ on ice. Then protein concentration was quantified using BCA protein assay kit. After centrifugation, $1 \mathrm{mg}$ total cell lysates were divided to incubate with anti-caspase- 8 primary antibody (1:500). After reaction for $2 \mathrm{~h}$, the protein $\mathrm{A} / \mathrm{G}$ agarose beads were added $(1: 200, v / v)$ for probing the protein-antibody complexes and the mixture was incubated overnight at $4{ }^{\circ} \mathrm{C}$. After denaturation in loading buffer by boiling, the clear supernatant was collected by centrifugation and subsequently subjected to Western blot analysis.

Statistical analysis. All data represented at least 3 independent experiments and are expressed as Average \pm SD unless otherwise indicated. To evaluate differences between control and treatment groups, a paired Student's $t$-test was performed. Differences among experimental groups were assessed using One-way ANOVA test. ${ }^{*} p$-value less than 0.05 was considered statistically significant.

\section{Results}

By introducing a methyl cyclohexane ring into the scaffold of CHAP, a novel synthetic analogue CTS203 (Fig. 1A) exhibited enhanced HDAC inhibitory activities was screened out [11]. Accordingly, CTS203 markedly increased the acetylated level of H3K14 (Fig. 1B), exhibiting at least 10\% higher efficiency than its precursor compound TSA (densitometric analysis, data not shown). Taken together, CTS203 is regarded as a promising candidate for cancer therapy and thus was selected for further investigation.

Cytotoxicity profile of CTS203. We examined the cytotoxicity of CTS203 against cancer cell lines comprising 3 solid tumor cell lines and 2 leukemia cell lines to investigate its anticancer efficiency and cell-type selectivity. Furthermore, two normal cell lines were applied (liver cancer cell line SMMC7721 corresponding human non-tumorous liver cell line LO2 and mouse primary hepatocytes) to evaluate its selectivity to cancer cells. All data were represented in Table 1.

Table 1. Cytotoxicity profile of CTS203

\begin{tabular}{|c|c|c|c|c|c|c|c|}
\hline \multirow[b]{2}{*}{ Compd. } & \multicolumn{4}{|c|}{$\mathrm{IC}_{50}(\mathrm{nM}), 48 \mathrm{~h}$} & \multicolumn{3}{|c|}{ Inhibitory ratio at $100 \mathrm{nM}(\times 100 \%), 24 \mathrm{~h}$} \\
\hline & MCF-7 & Hela & K562 & HL60 & SMMC-7721 & L02 & hepatocytes \\
\hline TSA & $141.80 \pm 3.73$ & $39.84 \pm 0.67$ & $560 \pm 55.12$ & $53.98 \pm 2.58$ & $44.72 \pm 6.82$ & $4.64 \pm 2.08$ & $1.20 \pm 1.24$ \\
\hline CTS203 & $26.33 \pm 1.05$ & $48.17 \pm 1.49$ & $104 \pm 14.06$ & $>1000[\mathrm{a}]$ & $47.24 \pm 1.91$ & $3.24 \pm 1.95$ & $7.76 \pm 2.58$ \\
\hline
\end{tabular}

[a] Inhibitory ratio less than $50 \%$ at the concentration of $1000 \mathrm{nM}$. Each value represents means \pm SD of three independent experiments. 
In general, CTS203 exhibited broad spectrum of anti-tumor efficiency against all cancer cell lines tested, with $\mathrm{IC}_{50}$ values in the nanomolar range. However, each individual cell line showed distinct sensitivity to CTS203. Notably, in comparison to TSA, MCF-7 and K562 cells were more sensitive to CTS203, with their $\mathrm{IC}_{50}$ values 5-fold lower than those of TSA, respectively. On the contrary, HL60 cell line showed an unexpected low sensitivity to CTS203, which may probably be ascribed to the distinct expression profile of class II HDAC subfamily members among cell lines and individually distinct HDAC inhibitory profiles among HDAC inhibitors $[11,14]$. MCF-7, the most sensitive cell line to CTS203, was selected for further investigation.
In addition, only subtle or bearable anti-proliferation effects on normal cells were observed after indicated treatment with TSA or CTS203. Noteworthy, CTS203 barely inhibited L02 cell proliferation $(<5 \%)$ at the concentration of $100 \mathrm{nM}$, while lead to nearly $30 \%$ decline in viability of SMMC-7721 cells correspondingly. These data indicated that CTS203 are tolerable for normal hepatic cells, thus selectively affected cancer cell lines.

Apoptotic cell death was predominant in CTS203induced cytotoxicity. Cell cycle arrest and apoptosis are two predominant cell death pathways induced by HDAC inhibitors. As revealed in our previous study, cell cycle distribution varied
A

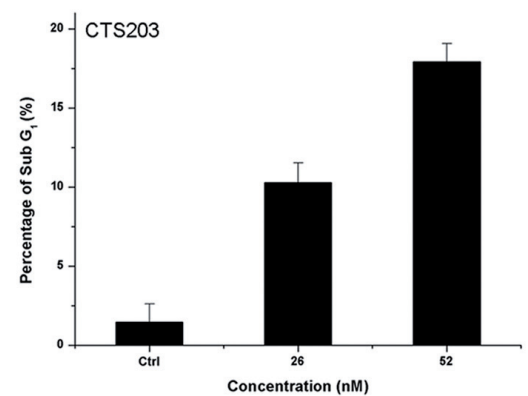

C

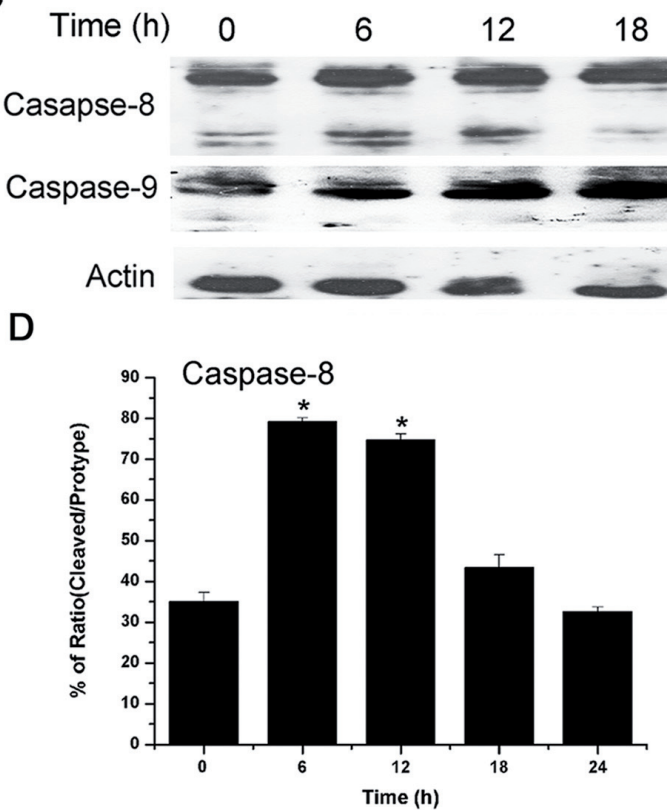

CTS203 (nM)

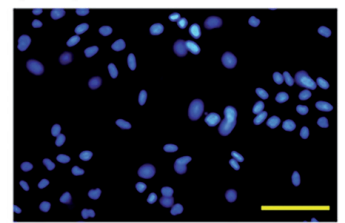

26

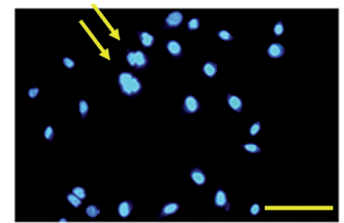

52

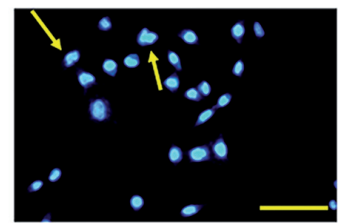

24

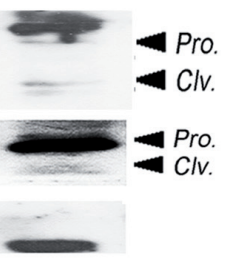

10

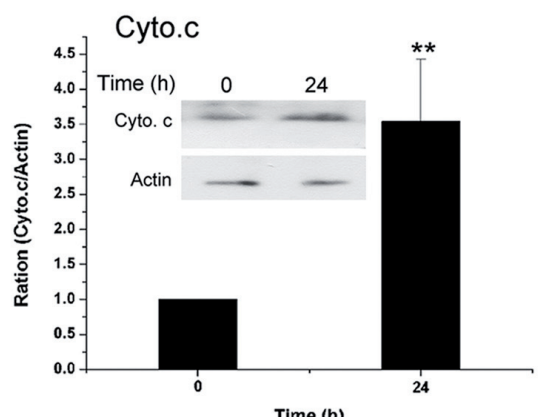

E

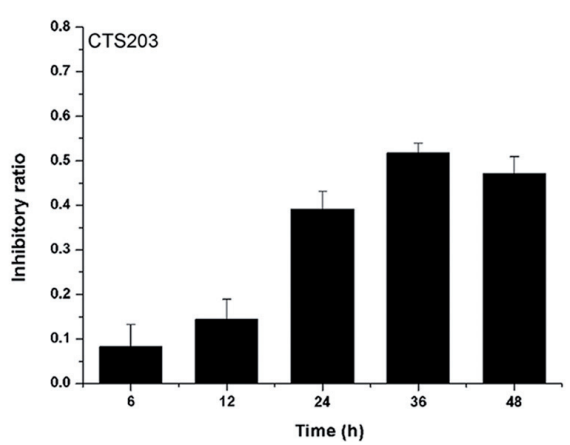

Figure 2. Effect of CTS203 on apoptosis in MCF-7 cells. (A) Accumulation of Sub G cells. Cells were harvested after $24 \mathrm{~h}$ treatment then analyzed by flow cytometry. (B) Morphologic changes aroused by CTS203. Cells were treated with indicated concentrations of CTS203 for $24 \mathrm{~h}$ before Hoechst 33342 staining. Cells appearing typical apoptotic morphology were indicated by arrows (Magnification $\times 200)$. (C) Expressions of apoptosis-associated proteins. Cells were treated for indicated time then subjected to Western blot analysis. Equal loading and transfer were verified by probing the membranes with $\beta$-actin antibody. (D) The activation ratio of apoptotic markers. The activation percentage of caspase- 8 was determined as the ratio between cleaved fragment and full-length prototype. The release of cytochrome $c$ was determined as the ratio between treated cells and untreated controls. Each corresponding result was determined form three independent experiments by comparing the relative intensities of protein bands. ${ }^{*} P<0.05$ as determined by Student's $t$-test. (E) Schedule-dependent cytotoxicity of CTS203. Cells were exposed to CTS203 for indicated time then removed into normal culture medium for a $24 \mathrm{~h}$ recovery before cell viability measurement. 
depending on CTS203 treatment, along with an accumulation of sub $\mathrm{G}_{1}$ cells, indicating the occurrence of apoptosis (Fig. $2 \mathrm{~A})$. Herein, to determine the occurrence of apoptotic cell death, cellular morphology and apoptotic-associated factors in caspase-3-deficient MCF-7 breast cancer cells were analyzed by Hoechst 33342 staining and Western blot.

Along with the cell cycle distribution alterations, typical apoptotic morphology appeared following CTS203 treatment. As shown in Fig. 2B, irregularly shaped nucleus and unevenly stained spots appeared after exposure to CTS203. More apoptotic cells were spotted after exposure to higher concentration of CTS203.

Accordingly, the expressions of apoptotic hallmarks were also affected by CTS203 (Fig. 2C, D). Cytochrome $c$ is one of the most prominent actors in apoptotic scene and its release form mitochondrial to cytosol is required for the activation of executor caspases [15]. As expected, cytochrome $c$ was released and accumulated in cytosol upon the treatment of CTS203. Likewise, the expression of caspase-9, the hallmark of intrinsic apoptotic pathway, was up-regulated during the treatment, along with a gradually accumulation of its active fragment. In contrast, the expression of caspase-8, the hallmark of extrinsic apoptotic pathway, was barely altered upon CTS203 treatment. Noteworthy, in response to pro-apoptotic stimuli, a short term elevation of active caspase- 8 appeared and then quickly vanished, indicating an instantaneous activation of caspase- 8 once exposure to CTS203. As an instant response to CTS203 stimuli, the cleavage of caspase- 8 might be function as a instant signal switch which associated with cell survival [16].

Schedule-dependent cytotoxicity of CTS203. Given the fact that hydroxamate derivatives are well known reversible inhibitors, thus the real-time cytotoxic stress they induced may probably be recoverable once the stimulus is withdrawn [17]. To determine the minimal exposure time of driving irreversible cellular damage, a recovery time was specially provided before viability measurement. As shown in Fig. 2E, during the whole treatment period, cell viability was gently declined in the first $12 \mathrm{~h}$, followed by a dramatically decline during $12 \mathrm{~h}$ to $36 \mathrm{~h}$, then merely stabilized in the last $12 \mathrm{~h}$. Notably, after additional recovery incubation, cell viability was barely affected (less than $15 \%$ ) by the previous treatment if the exposure duration was less than $12 \mathrm{~h}$. In contrast, prolonged treatment for more than $24 \mathrm{~h}$ led to permanent cytotoxicity, with a nearly $40 \%$ loss of cell viability. Taken together, these data indicated that a minimal exposure time of $12 \mathrm{~h}$ is necessarily required for CTS203 to induce cellular damage, which accidentally appearing a similar schedule to the accumulation of active caspase- 8 .

CTS203 induced cyto-protective autophagy in MCF-7 cells. Numerous evidences emerged to demonstrate the cytoprotective potential of autophagy, while several even wondered the involvement of autophagy in drug resistance [18-19]. Therefore, to investigate whether autophagy is triggered and whether its occurrence is responsible for the delayed response to CTS203 as revealed above, autophagic parameters were analyzed by immunofluorescence assay and Western blot.
During autophagosome formation, LC3 is specially recruited to the double-membrane vesicles after processing (conversion of LC3I to LC3II), thus the amount of LC3II is directly correlated with the extent of autophagy [20]. As shown in Fig. 3A, more fluorescent dots which represent the LC3II amount were spotted in cells treated with CTS203 as compared to vehicle-treated control. Notably, exposure to CTS203 lead to a rapidly increase in autophagic vacuoles within the first $12 \mathrm{~h}$ of treatment, followed by a serious decline in the next 12 $\mathrm{h}$, where the time switch is consistent with the threshold for causing irreversible damage. Accordingly, it is speculated that the delay of viability loss might be ascribed to the occurrence of autophagy during the early stage of treatment.

Similar to the observed morphology changes caused by CTS203, the ratio of LC3II/LC3I instantly increased within the first $12 \mathrm{~h}$ of treatment, and then dramatically declined (Fig. $3 \mathrm{~B}, \mathrm{C})$. However, unlike other chemo-stimulus such as SAHA, CTS203 alternatively promoted the expression of Beclin 1 [21]. Since Beclin 1 is necessary and sufficient for autophagy induction, these data implied the existence of potential regulators which are capable of manipulating the autophagy-initiating activity of Beclin 1 without affecting its expression [22]. Moreover, the cleavage of Beclin 1 was also noticed.

To determine whether CTS203-elicited autophagy is cytoprotective, a general inhibitor of autophagy 3-MA was used to disable the autophagic machinery. Three treatment conditions were compared: individual treatment with either CTS203 or 3-MA plus a combination treatment with both agents.

In the presence of 3-MA, cells were more sensitive to CTS203, appearing shorter response time and lower response concentration (Supplementary Fig S1). Furthermore, cell viability inhibition was markedly enhanced in the presence of 3-MA, along with an additional 20\%-30\% decrease in cell viability as compared to individual treatment with CTS203 or 3-MA, respectively (Fig. 4A). Subsequent statistical analysis revealed the combination effects of 3-MA and CTS203 are clearly synergistic, as determined by standard isobologram analysis (Fig. 4B). Notably, combined CTS203 and 3-MA treatment resulted in an enhanced effect on proliferation inhibition compared to each individual treatment, with a 35\%-50\% decrease in $\mathrm{IC}_{50}$ values, respectively. Collectively, these data indicated that CTS203-induced autophagy is cytoprotective, thus cell susceptibility to CTS203 was promoted after autophagy inhibition.

3-MA potentiated CTS203-mediated apoptotic cell death. Effects of autophagy inhibition on apoptosis were then examined. Morphological changes, apoptotic analysis and expression alterations of apoptotic hallmarks showed that apoptotic cell death was enhanced due to the coexistence of 3-MA and CTS203. Compared to the cells treated with CTS203, no obvious apoptotic morphology could be observed after exposure to 3-MA (Fig. 5A). In contrast, more anomalously stained pellets were spotted after combination treatment of CTS203 and 3-MA than CTS203 mono-treatment, which further confirmed the synergy of CTS203 and 3-MA. Notably, 
A

Time (h)

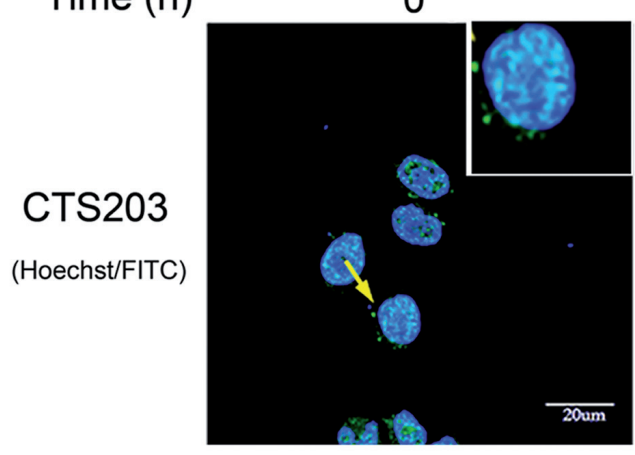

12

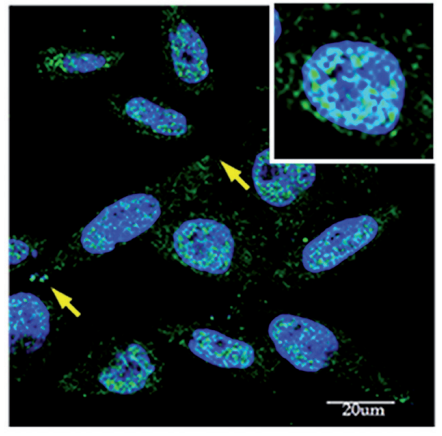

24

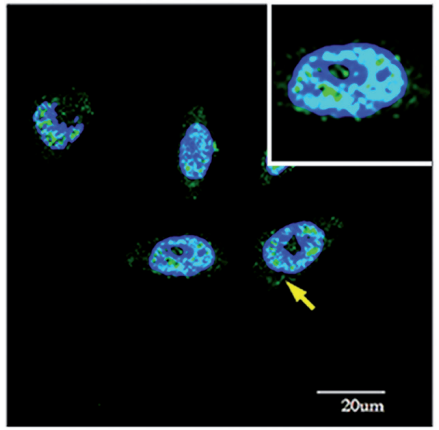

B
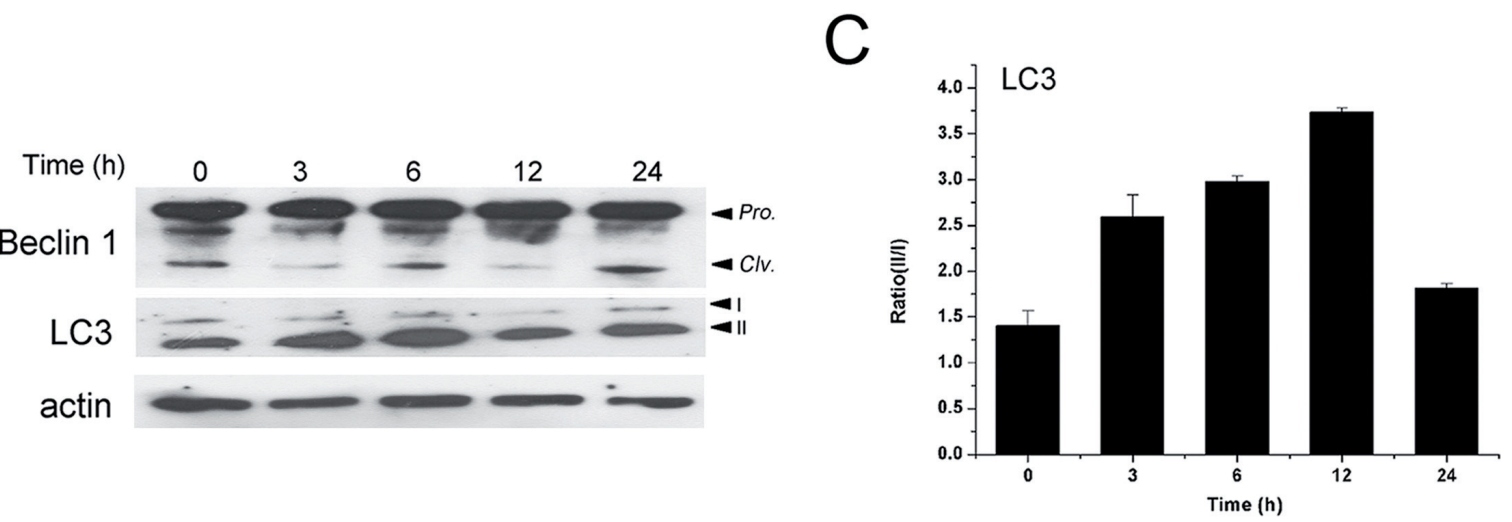

Figure 3. Cyto-protective autophagy induced by CTS203. (A) Autophagic morphology aroused by CTS203. After indicated treatment, cells were probed with anti-LC3 antibody, subsequently visualized by FITC-labeled secondary antibody, ultimately stained with Hoechst 33342 before microscopic measurement (Magnification $\times 1000$ ). Each inset is an enlarged image. (B) Expression level of autophagic markers. Cell extracts were prepared after indicated treatment times then subjected to Western blot analysis. Equal loading and transfer were verified by probing the membranes with $\beta$-actin antibody. (C) Conversion ratio of LC3II against LC3I. The results represented three independent experiments.
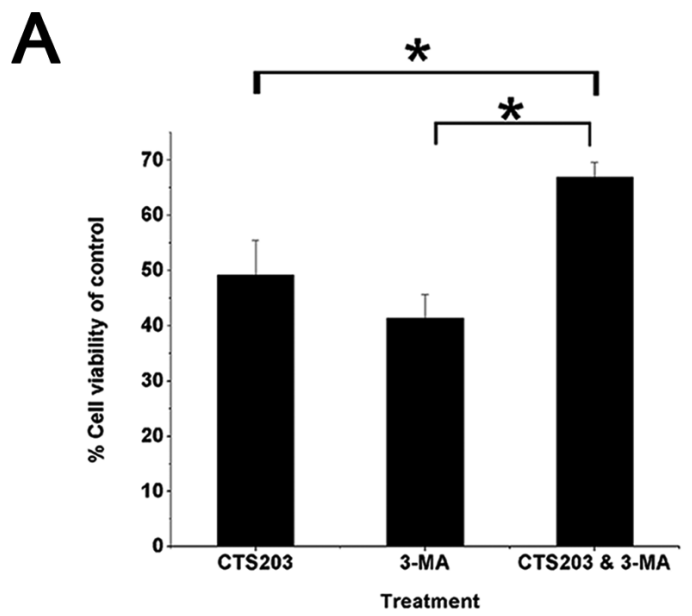
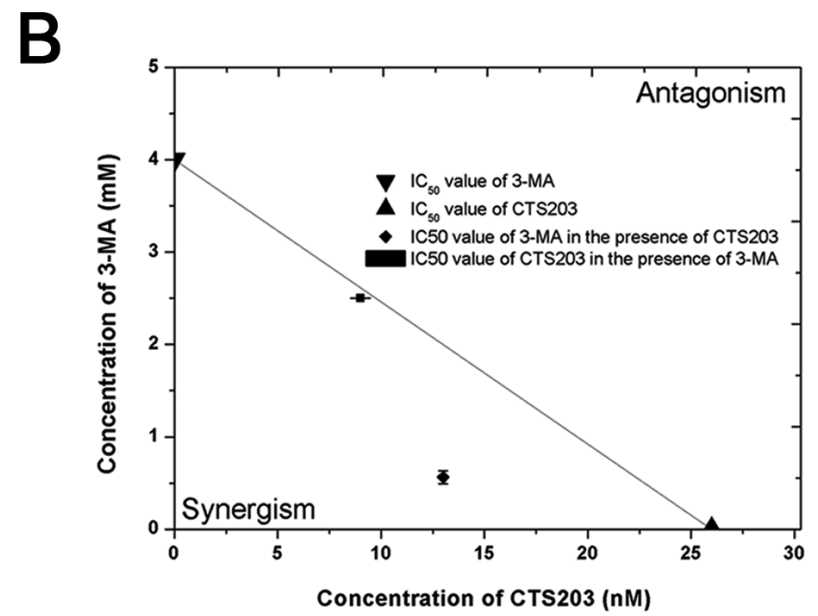

Figure 4. Synergistic effects between CTS203 and 3-MA. (A) 3-MA sensitized MCF-7 cells to CTS203. Cells were treated with CTS203 and 3-MA individually or synergistically for $24 \mathrm{~h}$ before viability measurement. ${ }^{*} P<0.05$ as determined by One-way ANOVA test. The concentration (IC ${ }_{50}$ value) of $3-M A$ applied in this experiment was determined as indicated in Supplementary Fig. S1. (B) Standard isobologram analysis. The IC $_{50}$ values of each compound (indicated by triangle and inverted triangle respectively) are plotted on the axes, the solid line represents the addictive effect. Points falling below the line indicate synergism between compound combinations, whereas those falling above indicate antagonism. All data represents at least three independent experiments. 
A

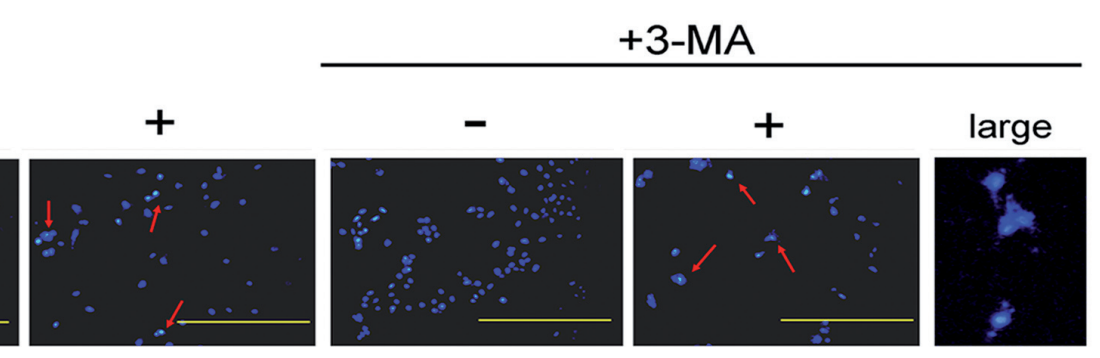

B

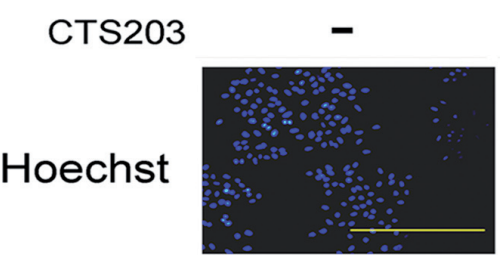

\section{C}
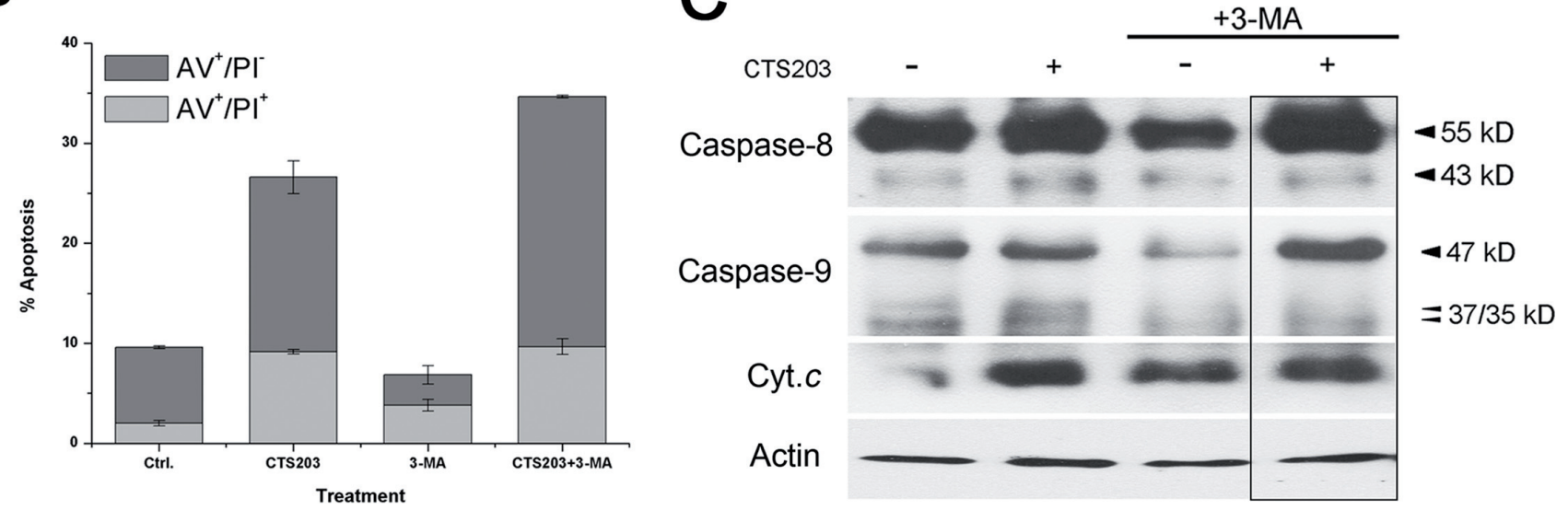

Figure 5. Participation of 3-MA facilitated CTS203-induced apoptotic cell death. (A) Effect of combination treatment on apoptotic morphology changes. Cells were stained with Hoechst 33342 after indicated treatment (Magnification $\times 200)$. (B) Analysis of apoptosis by flow cytometry. Cells were harvested after indicated treatment for $\mathbf{2 4} \mathrm{h}$ before Annexin V/PI staining. (C) Expression of apoptotic hallmarks. Cell extracts were prepared after indicated treatment for $24 \mathrm{~h}$ then subjected to Western blot analysis. Equal loading and transfer were verified by probing the membranes with $\beta$-actin antibody.

the percentage of apoptotic cells was significantly increased after combination treatment, along with a $10 \%$ increase in comparison to prolonged CTS203 mono-treatment (Fig. 5B). Accordingly, combined treatment with CTS203 and 3-MA led to the accumulation of caspases (Fig. 5C) whereas no obvious effect on these factors was found upon 3-MA mono-treatment (Supplementary Fig S2). Unexpectedly, compared to the cells under CTS203 treatment, the participation of 3-MA barely promoted the cytoplasmic accumulation of cytochrome $c$. Therefore, a cytochrome $c$-independent pro-apoptotic pathway might be responsible to augment apoptotic cell death, which implying the participation of caspase-8-associated cell death pathway.

Apoptotic cell death was promoted via caspase-8-mediated Beclin 1 cleavage. As a recently identified substrate of caspases, the cleavage of Beclin 1 would lead to autophagy deficiency [23]. To determine whether CTS203-induced autophagy was indeed inhibited via Beclin 1 cleavage due to the addition of 3-MA, the expression of autophagic hallmarks were then examined. In contrast to apoptotic markers, the expressions of Beclin 1 and LC3II were repressed upon combination treatment of CTS203 and 3-MA, though the exposure merely sustained for $12 \mathrm{~h}$ (Fig. 6A). In contrast to the up-regulation effect of CTS203 mono-treatment on the expression of Bec- lin 1 and the conversion of LC3, the participation of 3-MA overwhelmed this up-regulatory effect and resulted in a dramatically decrease. Besides expression suppression, cleaved fragments were markedly accumulated after combined treatment as compared to vehicle-treated control. As summarized in densitometric analysis (Data not shown), combination treatment resulted in an identical cleavage pattern (cleaved fragments) as compared to 3-MA mono-treatment. In contrast, the conversion from LC3I to LC3II was ultimately reduced upon combination treatment, though slightly increased upon CTS203 mono-treatment.

IP results then confirmed that caspase- 8 is an executor in Beclin 1 cleavage. As shown in Fig. 6B, synergistic treatment with CTS203 and 3-MA promoted the cleavage of Beclin 1, appearing a dramatically increase cleavage ratio as compared to prolonged CTS203 mono-treatment. As a consequence, apoptotic cell death was therefore enhanced in MCF-7 cells as previously indicated (Fig. 5). However, it seems like caspase-8 is not involved in 3-MA-induced cleavage of Beclin 1 (Fig. 6A), which might be ascribe to the fact that 3-MA could not affect caspase-8 expression/activation (Supplementary Fig S2). Collectively, these data suggested that cytotoxic potential of CTS203 could be fastened via manipulating the cleavage of Beclin 1. 


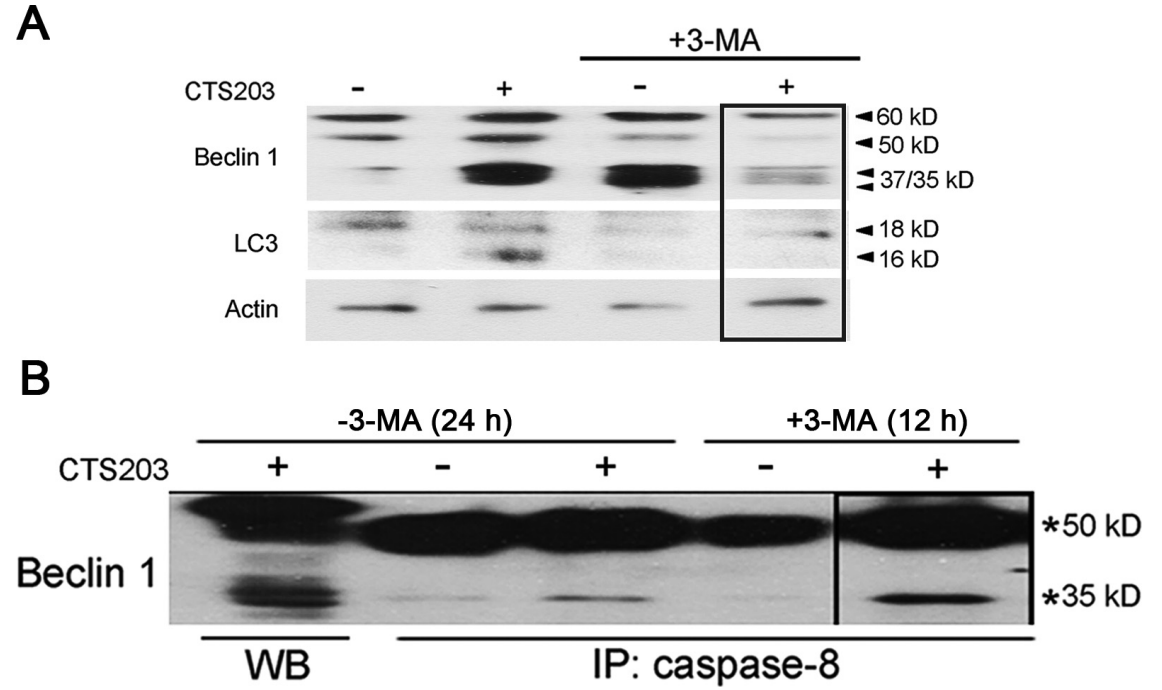

Figure 6. Caspase-8-mediated cleavage of Beclin 1 facilitated apoptotic cell death. (A) Expression of autophagic hallmarks. Whole cell extracts were prepared after indicated treatment for 12 $h$ then subjected to Western blot analysis. Equal loading and transfer were verified by probing the membranes with $\beta$-actin antibody. (B) The cleavage of Beclin 1 mediated by caspase-8. Cell extracts were prepared in gentle lysis buffer after indicated treatment, subsequently subjected to probe with primary anti-caspase- 8 antibody, then purified by protein $\mathrm{A} / \mathrm{G}$ agarose, followed by Western blot analysis. Cell extract (under CTS203 treatment for $24 \mathrm{~h}$ ) directly underwent Western blot was used as positive control. Equal loading and transfer were verified by BCA kit (data not shown).

\section{Discussion}

HDAC inhibitors have emerged as promising anti-cancer agents and have exhibited multiple anti-cancer activities as mono-therapy [24]. Though different individuals exhibit distinct anti-cancer profiles, most HDAC inhibitors are highly effective and well tolerable [25]. In this research, by assessment of cytotoxicity profile against diverse cell lines, CTS203 was identified as a potential anti-cancer candidate while tolerated in normal cells. Similar to classical HDAC inhibitors such as TSA and FK228, besides a $G_{2}$ cell cycle arrest, a caspase9-dependent apoptotic cell death was consequently induced by CTS203 (Fig. 2). However, though caspase- 8 was quickly elicited in response to CTS203 treatment, our results revealed a delayed cytotoxicity.

Besides induction of apoptosis, autophagy could be simultaneously induced by HDAC inhibitors [26]. Likewise, more autophagic vacuoles and increased expression/conversion of autophagic hallmarks appeared after exposure to CTS203, both indicating the simultaneously occurrence of autophagy (Fig. 3). Though many studies support the notion that autophagy is an alternative programmed cell death pathway to apoptosis, numerous researches indicated the cyto-protective effect of autophagy [18-19]. Classical HDAC inhibitor FK228, has been reported capable of triggering cyto-protective autophagy [27]. Similarly, due to the occurrence of autophagy, prolonged "treatment duration or higher dose are required for causing inevitable cellular damage (Fig S1). Accordingly, once the autophagy was inhibited by 3-MA, MCF-7 cells became more sensitive to CTS203, implying a synergism between CTS203 and 3-MA (Fig. 4).

Interestingly, the cyto-protective autophagy induced by CTS203 merely sustained for $12 \mathrm{~h}$, then quickly reduced or nearly vanished. Correspondingly, caspase- 8 coincidently showed a similar peak expression within this very period.
Given the amount of Beclin 1 was barely affected by CTS203, it is speculated caspase-8-mediated cleavage of Beclin 1 contribute to overwhelming the cyto-protective effect aroused by autophagic machinery (Fig. 3B). Therefore, cells endured longer exposure time would ultimately undergo apoptosis (Fig. 5).

The crosstalk between apoptosis and autophagy has been widely investigated, however, not fully understood yet. As recently indicated, the competition between caspase- 8 and Beclin1 plays a predominant role in cell-fate determination. By triggering caspase-mediated cleavage of Beclin 1, the obtained fragments would re-localized and promote apoptotic cell death; on the contrary, the full-length Beclin 1 are capable of digesting active-caspase- $8[25,28]$. In our results, the active caspase- 8 was dramatically declined while the occurrence of autophagy upon CTS203 mono-treatment (Fig. 2C), implying the necessity of autophagy inhibition in magnifying apoptotic signal. Furthermore, autophagy likewise delayed apoptosis via interrupting the caspase cascade during camptothecin treatment, which further emphasizing the therapeutic significance of autophagy inhibition [29]. Therefore, a prolonged CTS203 mono-treatment or the addition of 3-MA ultimately redirected MCF-7 cells to apoptosis via caspase-8-driven cleavage of Beclin 1 (Fig. 5), which is in consistent to the pro-apoptotic role of cleaved Beclin 1 fragments [25, 30]. However, no further accumulation of cytochrome $c$ was observed though the expression of caspase- 9 was further up-regulated upon combination treatment as compared to CTS203 mono-treatment, implying a complementary role of caspase-8 [31].

Synergistic treatment is more effective and more preferred in recent clinical trials [32]. Similar to the advantages obtained from combination therapy in leukemia treatment [33], the mixture of 3-MA and CTS203 also exhibited a synergistic effect against MCF-7 cells (Fig. 4). Notably, the onset of CTS203-elicited response was much faster and more sensitive 
in the presence of 3-MA, which also implying the necessity of autophagy inhibition in anti-cancer treatment. In addition, an expression profile of a recently derived CTS203-resistant MCF-7 cells revealed a hyper-expression of Beclin 1 (Supplementary Fig S3), suggesting the positive correlation of Beclin 1 to acquired drug resistance. Taken together, targeting Beclin 1 along with certain chemo-stimuli would be an appropriate strategy to enhance therapeutic effect and thus to avoid acquired drug resistance.

In summary, we identified CTS203 as an excellent anticancer agent with broad anti-cancer activity, whereas no significant influences on normal cells were observed. Our study showed apoptosis and autophagy were both triggered upon CTS203 treatment. Co-existence of CTS203 and 3-MA promoted the cleavage of Beclin 1, and ultimately enhanced apoptotic cell death via a caspase-9-dependent pathway. Our findings suggested that appropriate inhibition of cytoprotective autophagy is necessary for certain anti-cancer treatment. Namely, autophagy would be a promising target to avoid acquired HDAC inhibitor-resistance.

Supplementary information is available in the online version of the paper.

Acknowledgements: We thank Dr. N. Nishino (Kyushu Institute of Technology, Japan) for providing unnatural amino acids for the preparation of CTS203. We thank Dr. Y. Dong (Dalian University of Technology, China) for providing Kunming mice.

\section{References}

[1] MARKS PA, MILLER T, RICHON VM. Histone deacetylases. Curr Opin Pharmacol 2003; 3: 344-351. http://dx.doi. org/10.1016/S1471-4892(03)00084-5

[2] PEART MJ, SMYTH GK, VAN LAAR RK, BOWTELL DD, RICHON VM et al. Identification and functional significance of genes regulated by structurally different histone deacetylase inhibitors. PNAS 2005; 102: 3697-3702. http://dx.doi. org/10.1073/pnas.0500369102

[3] GLASER KB, STAVER MJ, WARING JF, STENDER J, ULRICH RG et al. Gene expression profiling of multiple histone deacetylase (HDAC) inhbitors: defining a common gene set produced by HDAC inhibition in T24 and MDA carcinoma cell lines. Mol Cancer Ther 2003; 2:151-163.

[4] BANTSCHEFF M, HOPF C, SAVITSKI MM, DITTMANN A, GRANDI P et al. Chemoproteomics profiling of HDAC inhibitors reveals selective targeting of HDAC complexes. Nat Biotechnol 2011; 29: 255-265. http://dx.doi.org/10.1038/nbt.1759

[5] SHIMIZE S, KANASEKE T, MIZUSHIMA N, MIZUTA T, ARAKAWA-KOBAYASHI $S$ et al. Role of Bcl-2 family proteins in a non-apoptotic programmed cell death dependent on autophagy genes. Nat Cell Biol 2004; 6: 1221-1228. http:// dx.doi.org/10.1038/ncb1192

[6] MILLS KR, REGINATO M, DEBNATH J, QUEENAN B, BRUGGE JS. Tumor necrosis factor-related apoptosis-inducing ligand (TRAIL) is required for induction of autophagy during lumen formation in vitro. PNAS 2004; 101: 3438-3443. http://dx.doi.org/10.1073/pnas.0400443101

[7] ESKELINEN EL. The dual role of autophagy in cancer. Curr Opin Pharmacol 2011; 11: 294-300. http://dx.doi. org/10.1016/j.coph.2011.03.009

[8] SUN W, CHEN J, WANG Y, ZHENG H. Autophagy protects breast cancer cells from epirubicin-induced apoptosis and facilitates epirubicin-resistance development. Autophagy 2011; 7: 1035-1044. http://dx.doi.org/10.4161/auto.7.9.16521

[9] CHEN S, KEHMAN SK, ZHANG W, WEN A, YAO L et al. Autophagy is therapeutic target in anticancer drug resistance. BBA-Rev Cancer 2010; 1806: 220-229.

[10] PONTIKI E, HADJIPAVLOU-LITINA D. Histone deacetylase inhibitors (HDACIs). Structure-activity relationships: history and new QSAR perspectives. Med Res Rev 2012; 32: 1-165. http://dx.doi.org/10.1002/med.20200

[11] WANG S, LI X, WEI Y, XIU Z, NISHINO N. Discovery of potent HDAC inhibitors based on Chlamydocin with inhibitory effects on cell migration. ChemMedChem 2014; 9: 627-637. http://dx.doi.org/10.1002/cmdc.201300372

[12] SIEGEL R, NAISHADHAM D, JEMAL A. Cancer Statistics, 2013. CA Cancer J Clin 2013; 63: 11-30. http://dx.doi. org/10.3322/caac. 21166

[13] GUARNERI V, FRASSOLDATI A, GIOVANNELLI S, BORGHI F, CONTE P. Primary systemic therapy for operable breast cancer: a review of clinical trials and perspectives. Cancer Lett 2007; 248: 175-185. http://dx.doi.org/10.1016/j. canlet.2006.07.001

[14] BRADBURY CA, KHANIM FL, HAYDEN R, BUNCE CM, WHITE DA et al. Histone deacetylases in acute myeloid leukemia show a distinctive pattern of expression that changes selectively in response to deacetylase inhibitors. Leukemia, 2005; 9: 1751-1759. http://dx.doi.org/10.1038/sj.leu.2403910

[15] GARRIDO C, GALLUZZI L, BRUNET M, PUIG PE, DIDELOT C et al. Mechanisms of cytochrome $\mathrm{c}$ release from mitochondria. Cell Death Differ 2006; 13: 1423-1433. http:// dx.doi.org/10.1038/sj.cdd.4401950

[16] VANDENABEELE P, BERGHE TV, FESTJENS N. Caspase inhibitors promote alternative cell death pathways. Sci. STKE 2006; 358: pe44.

[17] MURI EMF, NIETO MJ, SINDELAR RD, WILLIAMSON JS. Hydroxamic acids as pharmacological agents. Curr Med Chem 2002; 9: 1631-1653. http://dx.doi. org/10.2174/0929867023369402

[18] XI G, HU X, WU B, JIANG H, YOUNG CTF, PANG Y et al. Autophagy inhibition promotes paclitaxel-induced apoptosis in cancer cells. Cancer lett 2011; 307: 141-148. http://dx.doi. org/10.1016/j.canlet.2011.03.026

[19] HE G, WANG Y, PANG X, ZHANG B. Inhibition of autophagy induced by TSA sensitizes colon cell to radiation. Tumor Biol 2014; 35: 1003-1011. http://dx.doi.org/10.1007/s13277-0131134-Z

[20] KABEYA Y, MIZUSHIMA N, UENO T, YAMAMOTO A, KIRISAKO T et al. LC3, a mammalian homologue of yeast Apg8p, is localized in autophagosome membranes after processing. EMBO J 2000; 19: 5720-5728. http://dx.doi. org/10.1093/emboj/19.21.5720 
[21] CAO Q, YU C, XUE R, HSUEH W, PAN P et al. Autophagy induced by suberoylanilide hydroxamic acid in Hela S3 cells involves inhibition of protein kinase B and up-regulation of Beclin 1. Int J Biochem Cell B 2008; 40: 272-283. http://dx.doi. org/10.1016/j.biocel.2007.07.020

[22] YUE Z, JIN S, YANG C, LEVINE A J, HEINTZ N. Beclin 1, an autophagy gene essential for early embryonic development, is a haploinsufficient tumor suppressor. PNAS 2003; 100: 15077-15082. http://dx.doi.org/10.1073/pnas.2436255100

[23] VIRAWAN E, WALLE LV, KERSSE K, CORNELIS S, CLAERHOUT S et al. Caspase-mediated cleavage of Beclin-1 inactivates Beclin-1-induced autophagy and enhances apoptosis by promoting the release of proapoptotic factors from mitochondria. Cell Death Dis. 2010; doi:10.1038/ cddis.2009.16. http://dx.doi.org/10.1038/cddis.2009.16

[24] CHO DH, JO YK, HWANG JJ, LEE YM, ROH SA et al. Caspase-mediated cleavage of ATG6/Beclin-1 links apoptosis to autophagy in Hela cells. Cancer Lett 2009; 274: 95-100. http://dx.doi.org/10.1016/j.canlet.2008.09.004

[25] LIU T, KULJACA S, TEE A, MARSHALL GM. Histone deacetylase inhibitors: multifunctional anticancer agents. Cancer Treat Rev 2006; 32: 157-165. http://dx.doi.org/10.1016/j. ctrv.2005.12.006

[26] HUANG SW, LIU KT, CHANG CC, CHEN YJ, WU CY et al. Imiquimod simultaneously induces autophagy and apoptosis in human basal cell carcinoma cells. Brit J Dermatol 2010; 163: 310-320. http://dx.doi.org/10.1111/j.1365-2133 $.2010 .09827 . \mathrm{x}$

[27] DEPERE-RICHER D, KINAL M, MENASCHE V, NIELSEN TH, RINCON SD et al. Vorinostat-induced autophagy switches from a death-promoting to cytoprotective signal to drive acquired resistance. Cell Death Dis. 2013; doi:10.1038/cddis.2012.210. http://dx.doi.org/10.1038/ cddis. 2012.210

[28] HOU W, HAN J, LU C, GOLDSTEIN LA, RABINOWICH H. Autophagic degradation of active caspase-8. Autophagy, 2010; 6: 891-900. http://dx.doi.org/10.4161/auto.6.7.13038

[29] Abedin MJ, McDonnell MA, Lehmann U, Kelekar A. Autophagy delays apoptotic death in breast cancer cells following DNA damage. Cell Death Differ 2007; 14: 500-510. http:// dx.doi.org/10.1038/sj.cdd.4402039

[30] ZHU Y, ZHAO L, LIU L, GAO P, TIAN W et al. Beclin 1 cleavage by caspase-3 inactivates autophagy and promotes apoptosis. Protein Cell 2010; 1: 468-477. http://dx.doi. org/10.1007/s13238-010-0048-4

[31] GILLENWATER AM, ZHONG M, LOTAN R. Hitone deacetylase inhibitor suberoylanilide hydroxamic acid induces apoptosis through both mitochondrial and Fas (CD95) signaling in head and neck squamous carcinoma cells. Mol Cancer Ther 2007; 6: 2967-2975. http://dx.doi.org/10.1158/15357163.MCT-04-0344

[32] CAREW JS, GILES FJ, NAWROCKI ST. Histone deacetylase inhibitors: mechanisms of cell death and promise in combination cancer therapy. Cancer Lett 2008; 269: 7-17. http://dx.doi. org/10.1016/j.canlet.2008.03.037

[33] XIE C, EDWARDS H, XU X, ZHOU H, BUCK SA et al. Mechanisms of synergistic antileukemic interactions between valproic acid and cytarabine in pediatric acute myeloid leukemia. Clin Cancer Res 2010; 16: 5499-5510. http://dx.doi. org/10.1158/1078-0432.CCR-10-1707 


\title{
Supplementary Information
}

\section{Autophagy inhibitor sensitizes MCF-7 breast cancer cells to novel cyclic tetrapeptide CTS203-induced caspase-9-dependent apoptotic cell death}

\author{
S. WANG ${ }^{1}, \mathrm{X} . \mathrm{LI}^{1, \star}, \mathrm{Q} . \mathrm{WANG}^{2}, \mathrm{Z} \cdot \mathrm{XIU}^{1}$
}

${ }^{1}$ School of Life Science and Biotechnology, Dalian University of Technology, Dalian 116024, China; ${ }^{2}$ School of Pharmaceutical Science and Technology, Dalian University of Technology, Dalian 116024, China

*Correspondence:lxhxh@dlut.edu.cn

Supplementary Figure

(a)

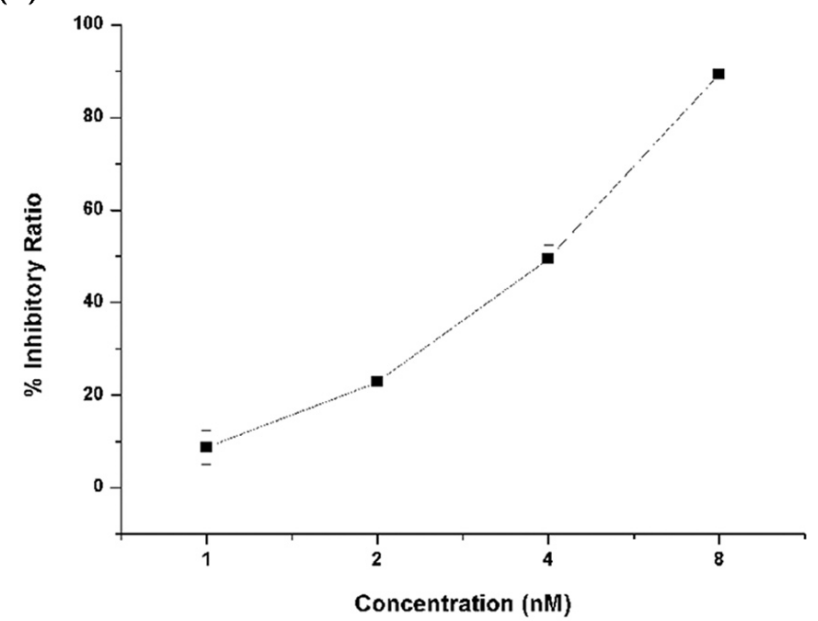

(c)

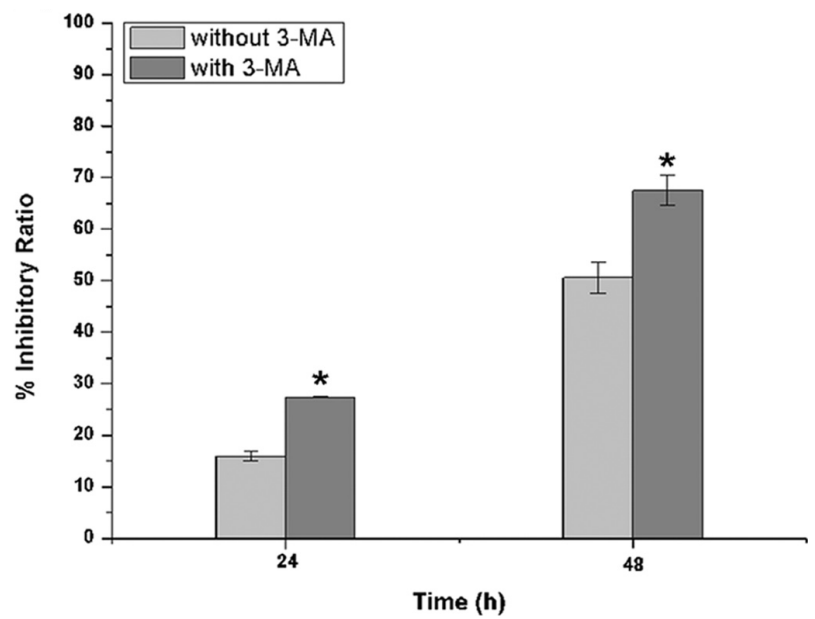

(b)

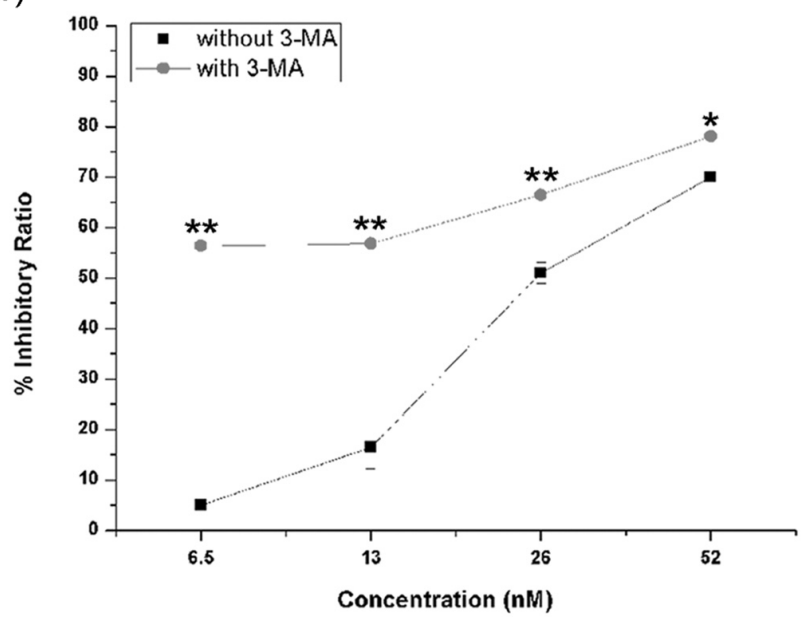

Figure S1 3-MA sensitized MCF-7 cells to CTS203. (a) Effects of 3-MA on cell viability. Cells were exposed to 3-MA with indicated concentrations for $48 \mathrm{~h}$ before viability measurement. (b) Effects of CTS203 on cell viability loss in the presence or absence of 3-MA. Cells were treated with indicated concentrations of CTS203 for $48 \mathrm{~h}$ in the presence or absence of 3-MA. (c) Schedule-dependent cytotoxicity of CTS203 in the presence or absence of 3-MA. Cells were treated with CTS203 for indicated hours in the presence or absence of 3-MA before subjected to measurement. Cell viability was measured by MTT assay and the results are expressed as the relative percentage of each treated group compared to vehicle control. Each data was determined from three independent experiments. ${ }^{*} \mathrm{P}<0.05$ and ${ }^{* \star} \mathrm{P}<0.01$ as determined by Student's t-test (b) or One-way ANOVA test (c). 


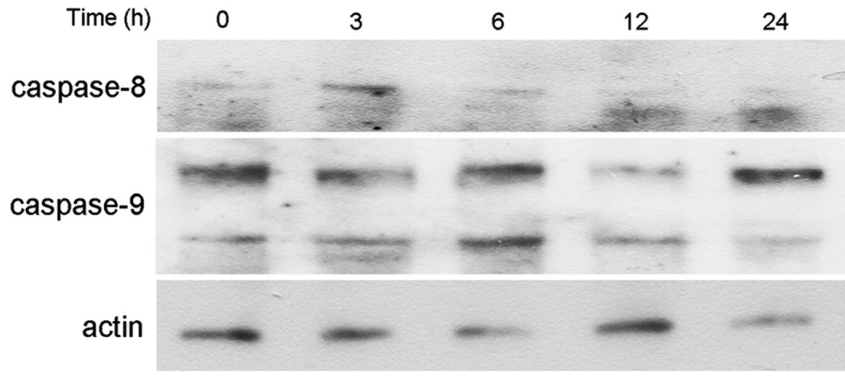

Figure S2 Effects of 3-MA on apoptotic hallmarks. Cells were treated with 3-MA for indicated hours before subjected to Western blot analysis. Equal loading and transfer were verified by probing the membranes with $\beta$-actin antibody.

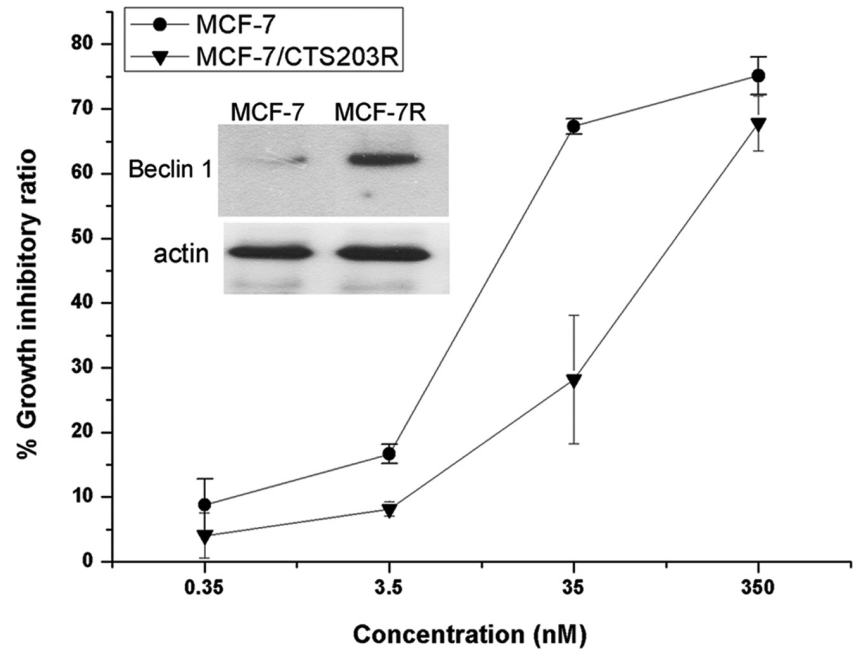

Figure S3 Expression of Beclin 1 in CTS203-resistance MCF-7 cells. Cells in logarithmic growth phase were harvested, lysed and subjected to Western blot analysis. Cell extracts of MCF-7 cells were used as standard reference. CTS203R MCF-7 cell lines were established by routinely exposure to CTS203. Equal loading and transfer were verified by probing the membranes with $\beta$-actin antibody. Cell viability was determined by MTT assay. 


\title{
Supplementary Information
}

\section{Autophagy inhibitor sensitizes MCF-7 breast cancer cells to novel cyclic tetrapeptide CTS203-induced caspase-9-dependent apoptotic cell death}

\author{
S. WANG ${ }^{1}, \mathrm{X} . \mathrm{LI}^{1, \star}, \mathrm{Q} . \mathrm{WANG}^{2}, \mathrm{Z} \cdot \mathrm{XIU}^{1}$
}

${ }^{1}$ School of Life Science and Biotechnology, Dalian University of Technology, Dalian 116024, China; ${ }^{2}$ School of Pharmaceutical Science and Technology, Dalian University of Technology, Dalian 116024, China

*Correspondence:lxhxh@dlut.edu.cn

Supplementary Figure

(a)

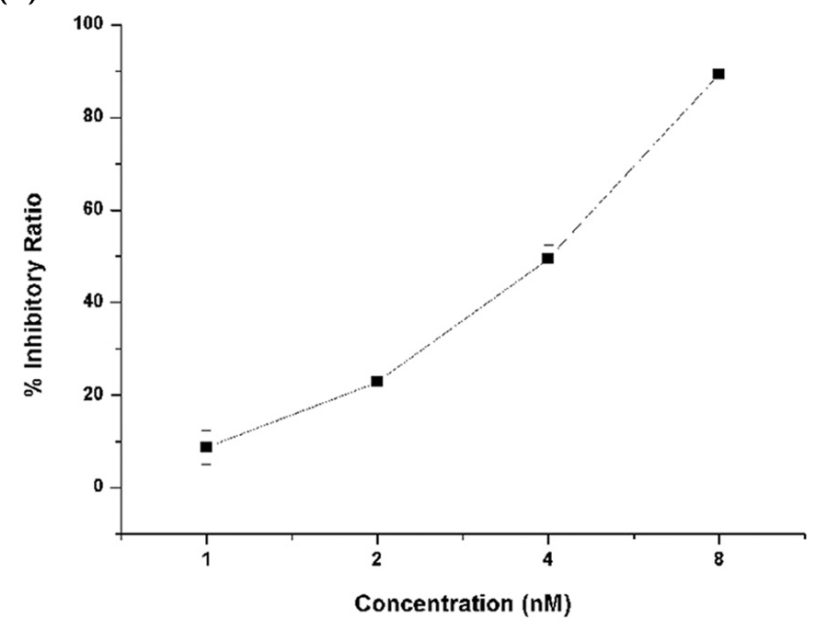

(c)

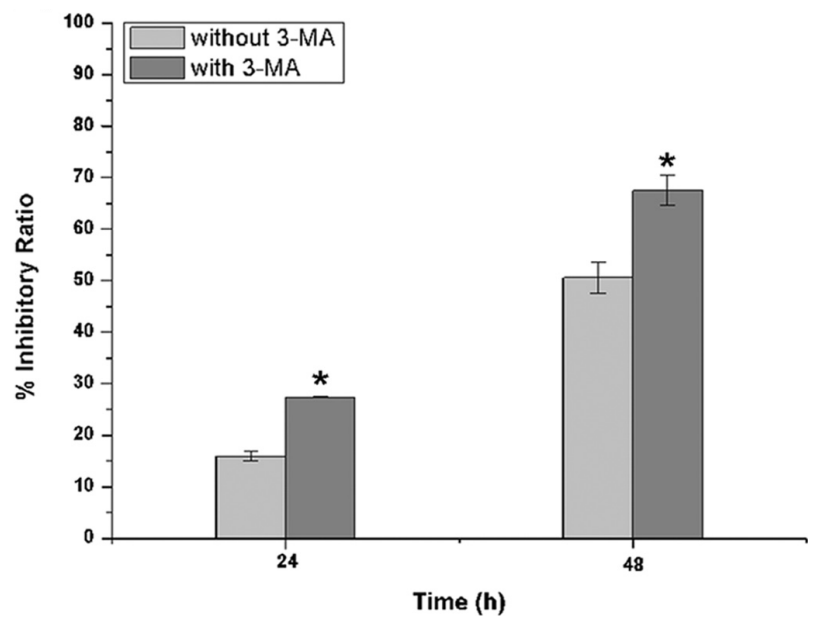

(b)

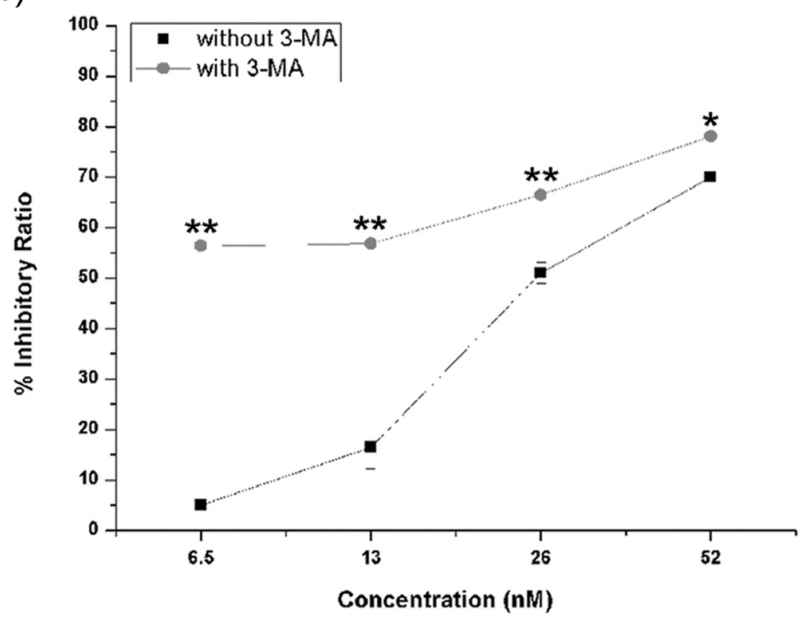

Figure S1 3-MA sensitized MCF-7 cells to CTS203. (a) Effects of 3-MA on cell viability. Cells were exposed to 3-MA with indicated concentrations for $48 \mathrm{~h}$ before viability measurement. (b) Effects of CTS203 on cell viability loss in the presence or absence of 3-MA. Cells were treated with indicated concentrations of CTS203 for $48 \mathrm{~h}$ in the presence or absence of 3-MA. (c) Schedule-dependent cytotoxicity of CTS203 in the presence or absence of 3-MA. Cells were treated with CTS203 for indicated hours in the presence or absence of 3-MA before subjected to measurement. Cell viability was measured by MTT assay and the results are expressed as the relative percentage of each treated group compared to vehicle control. Each data was determined from three independent experiments. ${ }^{*} \mathrm{P}<0.05$ and ${ }^{* \star} \mathrm{P}<0.01$ as determined by Student's t-test (b) or One-way ANOVA test (c). 


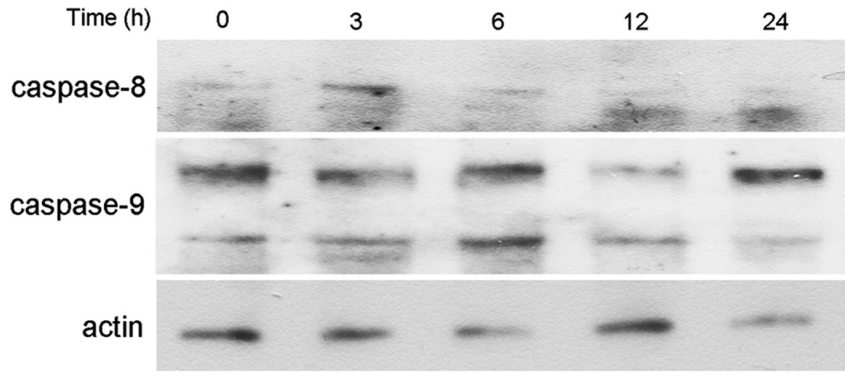

Figure S2 Effects of 3-MA on apoptotic hallmarks. Cells were treated with 3-MA for indicated hours before subjected to Western blot analysis. Equal loading and transfer were verified by probing the membranes with $\beta$-actin antibody.

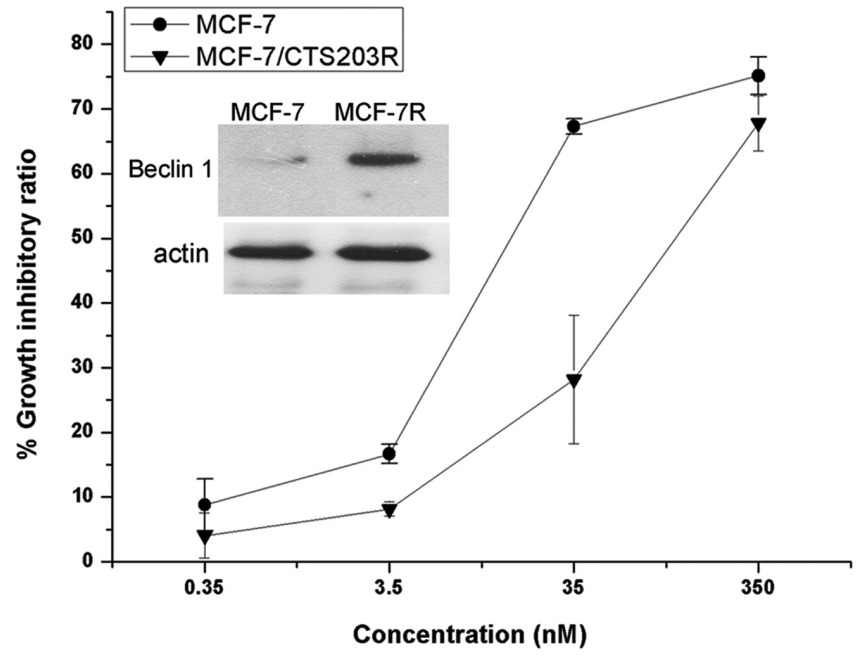

Figure S3 Expression of Beclin 1 in CTS203-resistance MCF-7 cells. Cells in logarithmic growth phase were harvested, lysed and subjected to Western blot analysis. Cell extracts of MCF-7 cells were used as standard reference. CTS203R MCF-7 cell lines were established by routinely exposure to CTS203. Equal loading and transfer were verified by probing the membranes with $\beta$-actin antibody. Cell viability was determined by MTT assay. 